\title{
Toxicity Analysis of Various Pluronic F-68-Coated Carbon Nanotubes on Mesenchymal Stem Cells
}

Meng-Zhu Yao ${ }^{1}$, Yu-Lan Hu ${ }^{1}$, Xiao-Xia Sheng ${ }^{2}$, Jun Lin ${ }^{3}$, Daishun Ling ${ }^{1 *}$, Jian-Qing Gao ${ }^{{ }^{*}}$

1. Institute of Pharmaceutics, College of Pharmaceutical Sciences, Zhejiang University, P.R.China, 866 Yuhangtang Road, Hangzhou 310058, Zhejiang, P.R.China.

2. Hangzhou SoliPharma Co., Ltd, 6th Street Hangzhou Economic and Technological Development Zone, Hangzhou 310058, Zhejiang, P.R.China.

3. First Affiliated Hospital, Medical College of Zhejiang University, Hangzhou 310058, Zhejiang, P.R.China.

Corresponding author: Jian-Qing Gao and Daishun Ling. Jian-Qing Gao, Email: gaojianqing@ zju.edu.cn Tel/Fax: +86-571-88208436; Daishun Ling, Email: lingds @ zju.edu.cn

Tel/Fax:+86-571-88208623

Funding: This study was supported in part by grants from National Science

Foundation of China (Grant No. 81271955). 


\begin{abstract}
Carbon nanotubes (CNTs) have poor colloid stability in biological media and exert cytotoxic effects on mesenchymal stem cells (MSCs). Modification with polymeric surfactant is a widely used strategy to enhance water dispersibility of CNTs. This study investigated the toxic effects of various Pluronic F-68 (PF68)-coated multi-walled CNTs (MWCNTs) on rat bone marrow-derived MSCs.PF68-coated MWCNTs showed favorable biocompatibility to MSCs that the cell viability, apoptosis, and reactive oxygen species (ROS) were not altered after $24 \mathrm{~h}$ of co-incubation. Nevertheless, significant apoptosis induction and massive ROS release were found following extended exposure (48 and $72 \mathrm{~h}$ ), and the toxic impact was dependent on the initial surface properties of the encapsulated MWCNTs. All the types of PF68-coated MWCNTs did not affect the cell-surface markers and in vivo biodistribution of MSCs. Our results suggest that proper polymer coating can reduce the acute toxicity of MWCNTs to MSCs but without altering their biological fate.
\end{abstract}

\title{
Keywords
}

Chemical functionalized carbon nanotubes; Pluronic F-68; Mesenchymal stem cells; Cytotoxicity; Biodistribution 


\section{Introduction}

The application of mesenchymal stem cells (MSCs) in the treatment of human diseases has remarkably increased in recent years [1, 2].MSCs are multipotent cells that can differentiate into multiple lineages, such as osteoblasts, chondrocytes, adipocytes, tenocytes, and neural cells. MSCs also demonstrate migratory capacity in vivo, in which they move to injury sites and thus treat neurological disorders, cardiac failure, diabetes, skin diseases, and bone or joint defects[3]. Given the admirable chemical stability, elasticity, mechanical strength and electrical conductivity of carbon nanotubes (CNTs), CNT composite substrates/scaffolds have been extensively studied to control the growth and differentiation of stem cells [4-7]. CNTs are also capable of tracking and monitoring stem cell in vivo [8-11]. Moreover, CNTs have drawn attention for gene transfection with the expectation of generating minimum disturbance to the surrounding biosystem[12, 13]. However, despite the great potential, CNT applications are intrinsically dependent on the colloid stability of CNTs in biological environments, e.g. the poor dispersibility of CNTs often results in toxicity to stem cells [14-18]. Thus, surface modification of CNTs is considerable for excellent biocompatibility and successful biomedical applications.

Functionalization of CNT with biocompatible polymers is a widely used strategy to improve its dispersion [19-21] as well as providing good biocompatibility for applications in stem cell research. For example, Chaoet al. demonstrated that poly(acrylic acid)-grafted CNT thin films could promote neuron differentiation of human embryonic stem cells [22]; they also fabricated silk fibroin/CNT 
nanocomposite films, which could support bone mesenchymal stem cell (BMSCs) attachment and growth [23]. Nayak et al. demonstrated that polyethylene glycol modified CNTfilms are suitable scaffold materials for the proliferation and bone formation of bone marrow stem cells [24].

Pluronic, which consists of a central polyoxypropylene molecule and two hydrophilic chains flanked on both sides, is widely used to disperse nanomaterials including CNTs for biomedical applications. Pluronic F-68

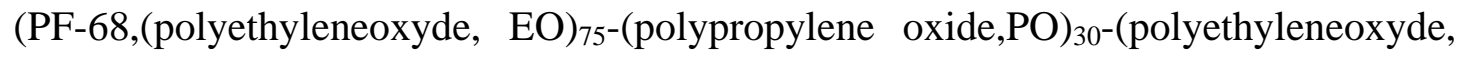
EO $)_{75}$ ) has been demonstrated to suppress cell apoptosis and is suggested to use as a cell protective agent in the treatment of thrombosis, stroke, and myocardial infarction [25, 26]. Furthermore, PF68 exerts cell protective effect on microcarrier bioreactor culture [26-28]. Luo et al. revealed that PF68 suppressed the activation of autophagy by decreasing LC3-II and Beclin-1 levels and remarkably reduced the infarct volume in a mouse middle cerebral artery occlusion (MCAO) model [29].In the present study, PF68 was used to improve the dispersibility of CNTs.

It is well known that different types of CNTs exert varying toxicity to stem cells [30], but the toxicity of various CNTs after being coated with identical polymer remains to be explored. The present study systemically monitored the toxicity index and cell function of MSCs treated with one typical polymeric surfactant, that is, PF68-coated multi-walled CNTs (MWCNT).

\section{Materials and Methods}




\subsection{Materials}

Pristine MWCNT (Cat.No.TNSM5), MWCNT-COOH (Cat.No.TNSMC5), MWCNT-OH (Cat.No.TNSMH5) were purchased from Chengdu Organic Chemicals, Chinese Academy of Sciences (Chengdu, China). Dulbecco's Modified Eagle's Medium (Cat. No. SH30027.01) were provided by Hyclone (Logan, Utah), fetal bovine serum (FBS, Gibco), SD Rat MSC osteogenic differentiation medium was provided by Cyagen. CD34, CD73, CD45, CD90 and Annexin V-FITC/Propidium Iodide Apoptosis Detection Kit were purchased from BD Biosciences. SD Rat MSC osteogenic differentiation medium (Cyagen), Rabbit Anti-VCL (Boster), WST-1,Cell Cycle Kit, ROS Assay kit, ALP Detection Kit, BCA protein Quantitation Assay and Actin-Tracker Green were purchased from Beyotime, Transwell (Coster), Reverse Transcription System and qRCR Master Mix were purchased from Promega.

\subsection{Animals}

Sprague Dawley (SD) rats (male, three weeks old) and nude mice (male, seven weeks old) were purchased from Shanghai SLAC Laboratory Animal Co., Ltd. (Shanghai, China). All animal experiments were performed with the approval of the Animal Experimental Ethics Committee of Zhejiang University. All animals were handled in accordance with the National Institutes of Health Guidelines for the Care and Use of Laboratory Animals.

\subsection{MWCNT Characterization and MWCNT Dispersion}


The length, diameter, and surface morphology of the three types of MWCNTs, pristine MWCNT (p-MWCNT), carboxylatedMWCNT (MWCNT-COOH), and hydroxylated MWCNT (MWCNT-OH), were measured using scanning electron microscopy (SEM, Hitachi TM-1000), and the surface chemical group was analyzed using X-ray photoelectron spectroscopy (XPS, Escalab 250Xi, ThermoFisher). PF68 with sterile deionized phosphate buffer solution (PBS) was prepared in a glass vial. PristineMWCNT, MWCNT-COOH, and MWCNT-OH powder were dispersed in PBS sonicated for $40 \mathrm{~min}$, and then dispersed in PF68 solution $(1 \% \mathrm{w} / \mathrm{v})$ with the final concentration of $1 \mathrm{mg} / \mathrm{mL}$. The samples prepared in PF68 (1\% w/v) were characterized by TEM (Hitachi H-7650), and the electrical properties of these PF/MWCNTs were detected using Mastersizer 2000.

\subsection{In vitro test}

\subsubsection{MSCs isolation, purification, culture, and identification}

Rat bone marrow-derived MSCs were isolated and cultured by adherence method. The surface markers of MSCs were examined by flow cytometry. The bone marrow of the femora of SD rats (3 weeks old) was harvested using a previously reported protocol [31]. Briefly, SD rats were euthanized by cervical dislocation, and the femora were explanted under aseptic conditions. The bone marrow was flushed out into 25 $\mathrm{mL}$ of a modified isolation medium including low-glucose Dulbecco's modified Eagle’s medium (DMEM), 10\% fetal bovine serum (FBS), L-glutamine, penicillin, and streptomycin by using a $20 \mathrm{~mL}$ injector, filtered through a sieve, and then 
centrifuged at 241gfor 5 min. The pellet was resuspended in $10 \mathrm{~mL}$ of modified DMEM-low glucose media. The suspension was then incubated in $25 \mathrm{~cm}^{2}$ flasks at $37^{\circ} \mathrm{C}$ in humidified atmosphere with $5 \% \mathrm{CO}_{2}$. The medium was refreshed after $48 \mathrm{~h}$ of culture and then replaced every other day. Cell passaging was performed when the cell confluence reached 90\%.The second-passage cells at sub-confluence were used for all experiments up to the fifth passages.

\subsubsection{WST-1 assay}

The third passage of MSCs was seeded in 96-well plates at a density of $1 \times 10^{4} / \mathrm{cm}^{2}$. After cell attachment, the cells were exposed to pristine MWCNT, MWCNT-COOH, MWCNT-OH, PF68/pristine MWCNT, PF68/MWCNT-COOH, and PF68/MWCNT -OH suspensions $(12.5,25,50$, and $100 \mu \mathrm{g} / \mathrm{mL})$ for 24,48 , and $72 \mathrm{~h}$, respectively. At the corresponding test time point, the control medium or test exposures were removed, each well was rinsed with PBS, and then $100 \mu \mathrm{L}$ fresh medium was (without FBS or supplements) was added into each well. The cell proliferation and cytotoxicity assay reagent (water soluble tetrazolium salt-1, WST-1) was subsequently added into each well and the plates were incubated at $37^{\circ} \mathrm{C}$ in a $5 \% \mathrm{CO}_{2}$ humidified incubator for $2 \mathrm{~h}$. The plate was shaken for $10 \mathrm{~min}$ and the absorbance was measured at $450 \mathrm{~nm}$. Six-well plates were used and each experiment was repeated independently three times.

\subsubsection{Intracellular ROS Generation}


Reactive oxidative stress (ROS) production in MSCs cultured with the three types of PF68/MWCNTs was measured using dichlorodihydrogen fluorescein-acetoacetic ester (DCFH-DA). The intensity of fluorescence is proportional to the amount of ROS produced in the cells. The third passage of MSCs was seeded in 96-well plates and cultured with the three types of PF68/MWCNTs $(12.5,25,50$, and $100 \mu \mathrm{g} / \mathrm{mL})$ for 24 , 48, and 72 h. At the testing time, the medium was discarded and washed with PBS three times. A volume of $100 \mu \mathrm{L}$ H2DCF-DA (final concentration of $10 \mu \mathrm{M}$ in the serum-free cell culture) was added into each well. The plates were incubated for 20 min at $37{ }^{\circ} \mathrm{C}$ and $5 \% \mathrm{CO}_{2}$ and then washed with serum-free cell culture thrice. Fluorescence was measured with a microtiter plate reader (VS Flash, Thermo, Ex = $488 \mathrm{~nm}$ and $\mathrm{Em}=525 \mathrm{~nm})$.

\subsubsection{IL-6 Expression}

Interleukin-6 (IL-6) expression was analyzed by reverse transcription quantitative real-time polymerase chain reaction (RT-qPCR).The third passage of BMSCs was seeded in a 6-well plate at a density of $1 \times 10^{5}$ cells $/ \mathrm{cm}^{2}$. When cell adherence reached around 70\%, the PF68/p-MWCNT, PF68/MWCNT-COOH, and PF68/MWCNT-OH $(12.5 \mu \mathrm{g} / \mathrm{mL})$ were added into each well. After $24 \mathrm{~h}$ culture time, the cells were washed two times with PBS and then centrifuged. The total RNA of collected cells in each group was extracted with Ultrapure RNA Kit (CWBIO) according to the protocol. The total RNA $(1 \mu \mathrm{g})$ was reverse transcribed to cDNA using GoScript ${ }^{\mathrm{TM}}$ Reverse Transcription System (Promega, USA) according to the 
manufacturer's protocol. The mRNA of IL-6 transcript was quantified from 100 ng of cDNA using GoTaq ${ }^{\mathrm{R}} \mathrm{qRCRMaster}$ Mix (Promega, USA) according to the manufacturer's protocols. Each sample was run in triplicate.

\subsubsection{Cell cycle}

The third passage of BMSCs was seeded in a 24-well plate at a density of $1 \times 10^{5}$ cells $/ \mathrm{cm}^{2}$. When cell adherence reached around 70\%, the PF68/p-MWCNT, PF68/MWCNT-COOH, and PF68/MWCNT-OH (12.5, 50, and $100 \mu \mathrm{g} / \mathrm{mL})$ were added into each well. After 24 h culture time, the cells were washed two times with PBS and then centrifuged. The collected cells were then fixed with $70 \%$ ethanol at $4{ }^{\circ} \mathrm{C}$ overnight. The treated cells were then resuspended in propidium iodide solution containing RNase and incubated in the dark at $37^{\circ} \mathrm{C}$ for $30 \mathrm{~min}$. The cell cycle was analyzed using a Flow Cytometer (FC500MCL, Beckman, Germany).

\subsubsection{Cell apoptosis}

The third passage of MSCs was seeded in six-well plate at a density of $2 \times 10^{5}$ cells per well and were cultured overnight. The cells were then treated with PF68/p-MWCNT, PF68/MWCNT-COOH, and PF68/MWCNT-OH (100 $\mu \mathrm{g} / \mathrm{mL})$. Untreated cells served as control groups. After 24 h exposure, cellular apoptosis were detected using Annexin V-FITC/PI apoptosis detection kit.

\subsubsection{PF68/MWCNT internalization}


Third-generation MSCs were separately exposed to PF68/p-MWCNT, PF68/MWCNT -COOH, and PF68/MWCNT-OH (12.5 $\mu \mathrm{g} / \mathrm{mL}$ respectively) for $24 \mathrm{~h}$. Treated cells were collected and pre-fixed with $2.5 \%$ glutaraldehyde solution, washed thrice in phosphate buffer, post-fixed with $1 \%$ OsO4 in phosphate buffer ( $\mathrm{pH} 7.0)$ for $1 \mathrm{~h}$, and then washed again thrice in phosphate buffer. The specimen was subsequently dehydrated by a graded series of ethanol (30\%, 50\%, 70\%, 80\%, 90\%, 95\%, and $100 \%$ ) for up to $15 \mathrm{~min}$ in each step and then transferred into absolute acetone for $20 \mathrm{~min}$. The specimen was placed in 1:1 mixture of absolute acetone and final Spurr resin mixture for $1 \mathrm{~h}$ at room temperature, transferred into 1:3 mixture of absolute acetone and final resin mixture for $3 \mathrm{~h}$, and then into final Spurr resin mixture overnight. The specimen was finally placed in capsules containing embedding medium and heated at $70{ }^{\circ} \mathrm{C}$ for approximately $9 \mathrm{~h}$, subsequently stained by uranyl acetate and alkaline lead citrate for $15 \mathrm{~min}$ each, and then observed via TEM (H-7650, Hitachi, Japan).

\subsubsection{Cytoskeleton and cell adhesion}

The third passage of MSCs was cultured with the three types of PF68/MWCNTs (12.5 $\mu \mathrm{g} / \mathrm{mL}$ respectively) for $24 \mathrm{~h}$. Cells were washed thrice in PBS, fixed with $4 \%$ paraformaldehyde at $4^{\circ} \mathrm{C}$ for $30 \mathrm{~min}$, and then permeabilized with $0.25 \%$ Triton X-100 for 10 min. Cells were then incubated with 5\% bovine serum albumin/PBS at $37^{\circ} \mathrm{C}$ for $1 \mathrm{~h}$. Afterward, rabbit monoclonal antibody against vinculin (1:100) was added and incubated overnight. Cy3 goat anti-rabbit secondary antibody (1:100) was 
then added and incubated at $37^{\circ} \mathrm{C}$ for another $1 \mathrm{~h}$. Cells were stained thereafter with Actin-Tracker Green for $30 \mathrm{~min}$ at room temperature in the dark and counterstained with Hoechst $33258(10 \mu \mathrm{g} / \mathrm{mL})$ at room temperature for $10 \mathrm{~min}$. Finally, cells were visualized using confocal laser scanning microscopy (LSM510 Meta, Zeiss, Germany).

\subsubsection{Cell migration in vitro}

Cell migration assay was performed using Transwell assay. BMSCs were cultured with the three types of PF68/MWCNTs $(12.5,25$, and $50 \mu \mathrm{g} / \mathrm{mL})$ for $24 \mathrm{~h}$. The treated cells were collected and seeded into a Millicell (Transwell ${ }^{\mathrm{R}}$ 3422, Corning, USA) containing pores of $8 \mu \mathrm{m}$ in diameter at an initial seeding density of $1 \times 10^{5}$ cells $/ \mathrm{cm}^{2}$ suspended in low-glucose DMEM (FBS-free). The Millicell was subsequently placed into a 24-well plate containing 10\% FBS in low-glucose DMEM, and the cells were allowed to migrate at $37^{\circ} \mathrm{C}$ for another $24 \mathrm{~h}$. The cells were subsequently stained with crystal violet (0.1 wt\%), and migrated cell clones were recorded using an optical microscope. The cell number was counted in five different areas.

\subsubsection{Cell differentiation}

The third passage of MSCs was seeded in a 24-well plate at a density of $1 \times 10^{4}$ cells/well. After 24 h, cells exposed to PF68/p-MWCNT, PF68/MWCNT-COOH, and PF68/MWCNT-OH were treated with $10 \%$ serum media containing osteogenic supplements (dexamethasone, ascorbic acid, and glycerophosphate) for 7 and 14 days. 
The media were replaced every 3 days. Cells were collected and lysed at the testing point, and supernatant was used to determine the alkaline phosphatase (ALP) activity with para-nitrophenyl phosphate as substrate and then cultured at $37^{\circ} \mathrm{C}$ for $20 \mathrm{~min}$. A reaction-terminated liquid $(100 \mu \mathrm{L})$ was subsequently added into each well. Absorbance at $405 \mathrm{~nm}$ was measured by a spectrophotometer with a 96-well microplate reader (Biotech, USA). The ALP activity of MSCs cultured without PF68/MWCNTs was used as control. ALP staining was conducted at the end point of the 7- and 14-day cultures. To quantify the differentiation process, real-time PCR was performed using the RNA of osteocalcin (OCN) and osteopontin (OPN) from the primary culture of cells unexposed or exposed to the three types of PF68/MWCNTs $(12.5 \mu \mathrm{g} / \mathrm{mL})$ in the lineage-specific induction media.

\subsection{MSCs biodistribution and Immunohistochemistry}

\subsubsection{MSCs biodistribution in vivo}

The third passage of MSCs treated or untreated with three types of PF68/MWCNTs $(12.5 \mu \mathrm{g} / \mathrm{mL})$ for $24 \mathrm{~h}$ was collected, and these cells were labeled with Dil $(1 \mu \mathrm{g} / \mathrm{mL}$, Molecular Probes ${ }^{\mathrm{R}}$, Life Technology). The Dil solution and cell suspensions were incubated for $30 \mathrm{~min}$ at $37^{\circ} \mathrm{C}$ and then for $15 \mathrm{~min}$ at $4{ }^{\circ} \mathrm{C}$, washed thrice with PBS, and subsequently resuspended in fresh medium. The Dil-labeled cells were injected into nude mice ( 7 weeks old) by cauda vein. At $72 \mathrm{~h}$ after I.V., the nude mice were anesthetized, perfused, and then dissected to collect the main organs. The biodistribution of Dil-labeled MSCs in the main organs was monitored using Maestro in vivo imaging system (CSHL, USA). 


\subsubsection{H\&E staining}

Heart, liver, lung, kidney and spleen were stained with hematoxylin/eosin(H\&E, nucleus and cytoplasm staining) for histologic examination. Paraffin-embedded organ sections were stained with hematoxylin and eosin. H\&E stained sections were scanned with the Leica SCN400 (Diegem, Belgium).

\subsection{Statistical analysis}

The data represent means $\pm \mathrm{SD}$ from three or more independent experiments as indicated. Statistical analysis was performed by Student's t test at a significance level of $p<0.05$.

\section{Results}

\subsection{MWCNT and PF68/MWCNT characterization}

SEM result (Figure 1A) showed that the average diameter of the three types MWCNTs were 20-30nm. X-ray photoelectron results of p-MWCNT, MWCNT-COOH and MWCNT-OH were demonstrated in Figure 1B. TEM result (Figure 1D) showed that the image of three types MWCNT dispersed in Pluronic-F68 (1\%) and revealed functionalized MWCNTs had better dispersibility than pristine MWCNT.The images of three types MWCNT dispersed in PBS or Pluronic-F68 (1\%) revealed functionalized MWCNTs had betterdispersibility than pristine MWCNT; Pluronic F68 (1\%) improved the dispersibility of MWCNTs in consistency with the 
result of particle size (Figure 1C\&1E). Zeta potential of MWCNTwas demonstrated in Figure 1F. Other detailed information of MWCNT was summarized in Table S1.
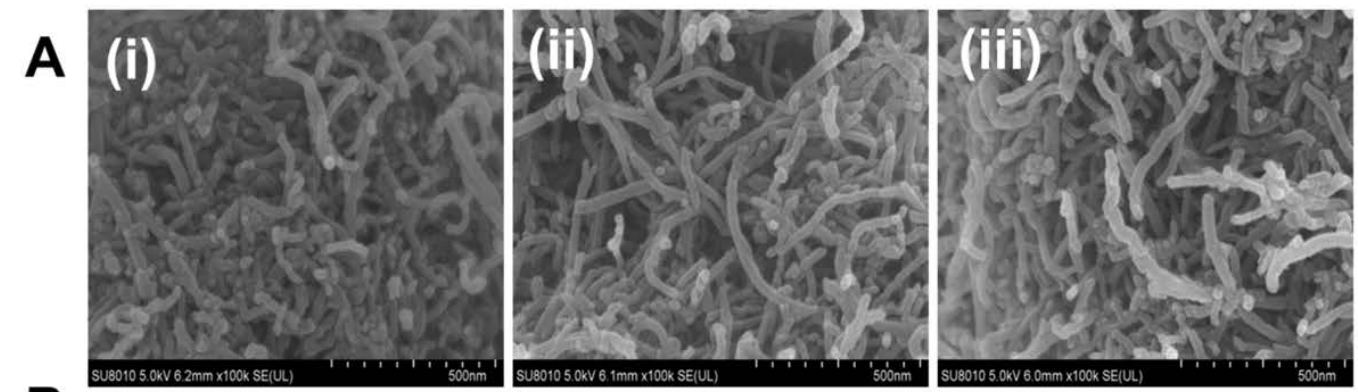

B
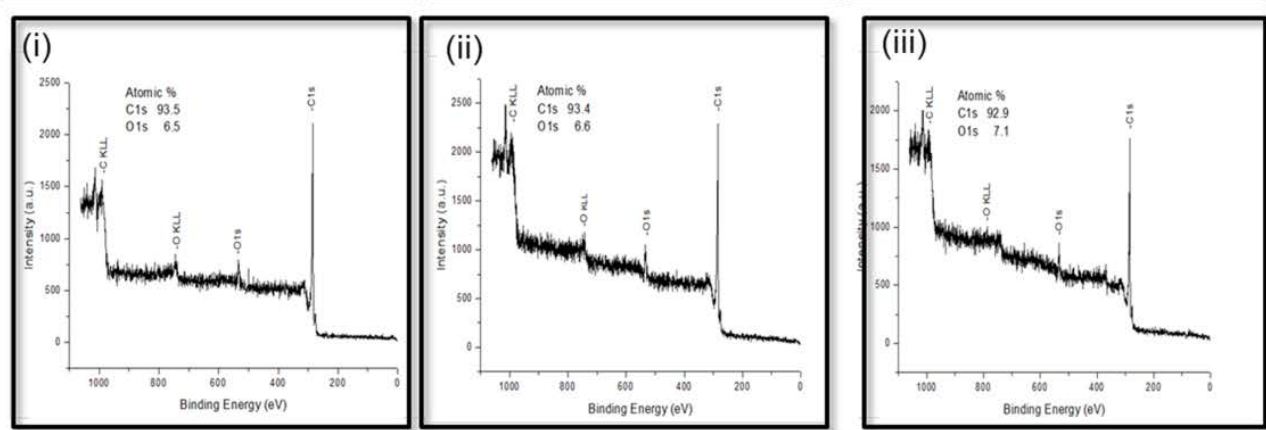

C
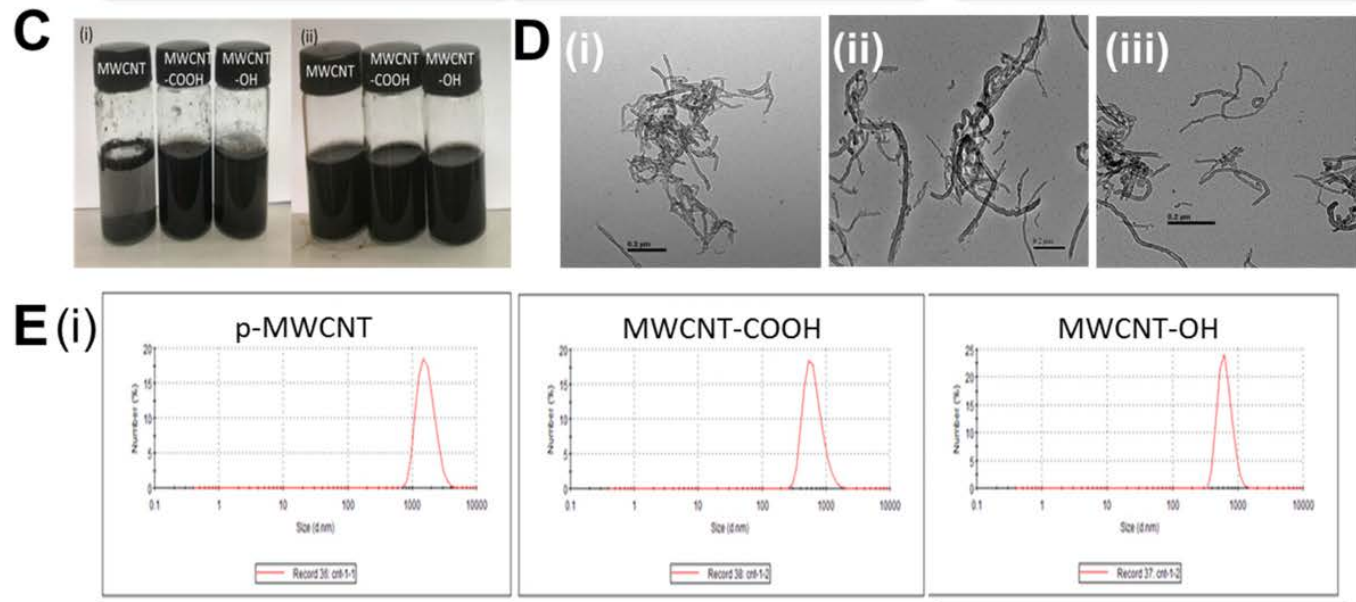

(ii)

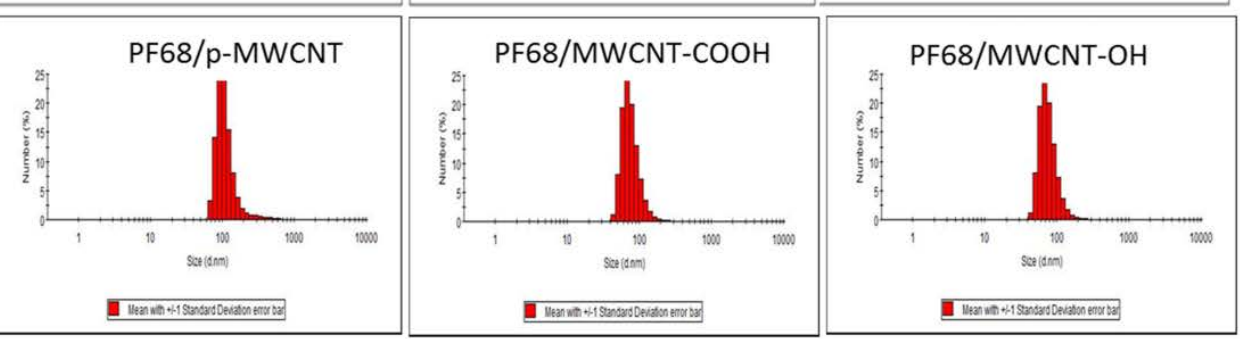

$\mathbf{F}$
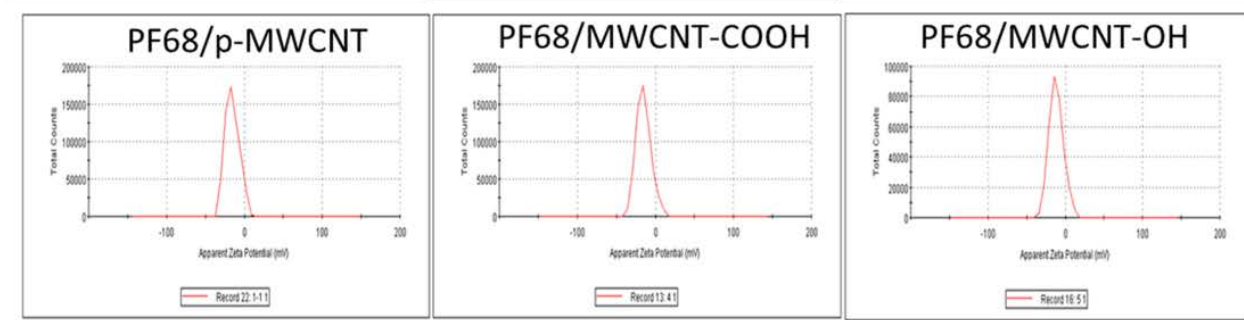
Figure 1.Characterization of MWCNT.(A) SEM images of (i) p-MWCNT, (ii) MWCNT-COOH, and (iii) MWCNT-OH.(B) Characterization of (i) p-MWCNT, (ii) MWCNT-COOH, and (iii) MWCNT-OH by XPS. (C) Dispersion state of the three types of MWCNT after sonication for $30 \mathrm{~min}$ in (i) PBS and (ii) PF68 (1\% w/v). (D) TEM images of (i) PF68/p-MWCNT, (ii) PF68/MWCNT-COOH, and (iii) PF68/MWCNT-OH. (E) Size distribution of MWCNT dispensed (i) in PBS and (ii) in PF68 (1\% w/v). (F) Zeta potential of MWCNT modified with PF68.

\subsection{In vitro toxicity of PF/MWCNTs to MSCs}

\subsubsection{Cell viability}

Cytotoxicity data were verified by WST-1. CNTs interact with some tetrazolium salts present in the MTT(methyl thiazolyl tetrazolium) system, thereby producing inaccurate results [32]. Figure2A-2C showed cell viability obviously decreased after exposure to P-MWCNT, MWCNT-COOH, and MWCNT-OH (12.5-100 $\mu \mathrm{g} / \mathrm{mL})$ for 24h, 48h, and $72 \mathrm{~h}$. The cytotoxicity of PF68/MWCNTs decreased compared with the cytotoxicity data of non-coatedMWCNTs(Figure 2D-2F). In detail, all concentrations of PF68/MWCNTs (12.5-100 $\mu \mathrm{g} / \mathrm{mL})$ did not induce cytotoxicity to MSCs after $24 \mathrm{~h}$ (Figure 2D). By contrast, the cytotoxicity of PF68/MWCNTs toward MSCs was noticed after 48 and $72 \mathrm{~h}$ of incubation (Figures $2 \mathrm{E}$ and $2 \mathrm{~F}$ ). After $72 \mathrm{~h}$ of incubation, a statistically significant $(* P<0.05)$ loss of viability (nearly $20 \%$ to $26 \%$ ) was observed in PF68/MWCNT-treated cells compared with the control group. and this effect was more evident in PF68/p-MWCNT. In addition, the effects of 
PF68/MWCNT-COOH and PF68/MWCNT-OH were statistically different from that of PF68/p-MWCNTs. These results demonstrated that even after polymer coating, the initial surface chemical functionalization of MWCNTs can still influence the long-term biocompatibility, which is possibly caused by the dissociation of the surface polymer and CNTs inside the cells following long-time incubation. Notably, the PF68-treated cells maintained high viability (>95\%).

A

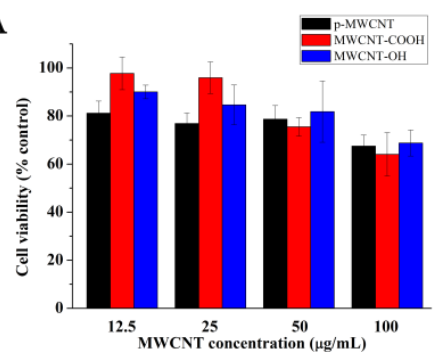

D

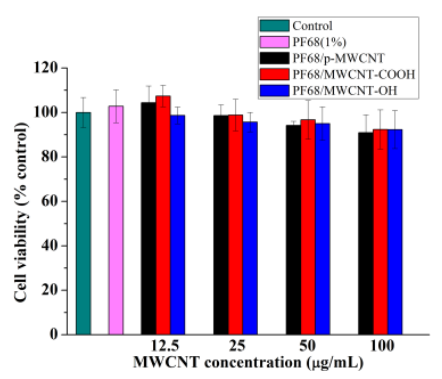

B

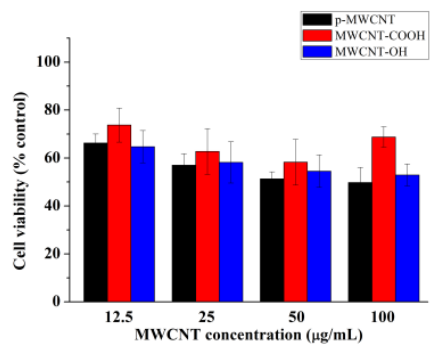

$\mathrm{E}$

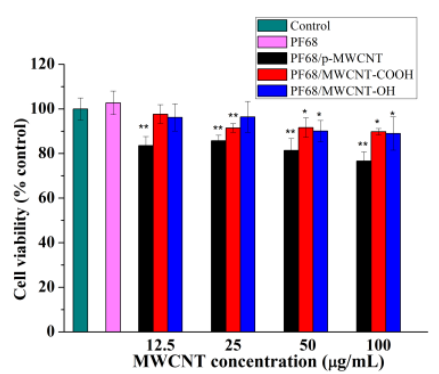

C

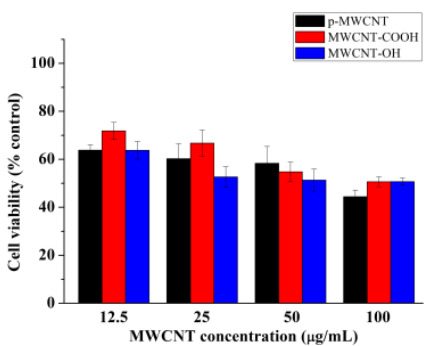

F

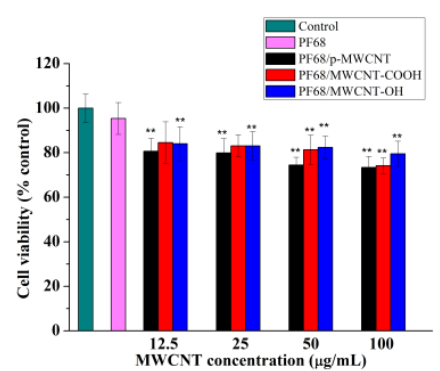

Figure 2.WST-1 assay. Cell viability after (A) 24h, (B) 48h, and (C) $72 \mathrm{~h}$ exposure to p-MWCNT, MWCNT-COOH, and MWCNT-OH (12.5-100 $\mu \mathrm{g} / \mathrm{mL})$;cell viability after (D) 24h, (E) 48h, and (F) 72h exposure to PF68/p-MWCNT, PF68/MWCNT-COOH and PF68/MWCNT-OH (12.5-100 $\mu \mathrm{g} / \mathrm{mL})$ and PF68(1\% w/v) . Results are expressed as percent of control means \pm standard deviation (vertical bars); $\mathrm{n}=6,{ }^{*} \mathrm{P}<0.05, * * \mathrm{P}<0.01$.

\subsubsection{ROS}

The ROS levels in PF68/MWCNT-treated cells were determined by a fluorescent 
method (DCFH-DA fluorescent probe). Figures 3A-3C showed a distinct dose- and time-dependent relationship between ROS level and PF68/MWCNT. After $24 \mathrm{~h}$ exposure to the three types of PF68/MWCNTs $(12.5-100 \mu \mathrm{g} / \mathrm{mL})$, the fluorescence intensity already increased significantly, following 48 and 72 h exposure, enormous ROS production was induced; in particular, PF68/p-MWCNT and PF68/MWCNT-OH (100 $\mu \mathrm{g} / \mathrm{mL}$ ) induced fluorescence intensity 10 times higher than that of the control group (Figures 3B and 3C).

\subsubsection{IL-6 level}

All three types of PF68/MWCNTs $(12.5 \mu \mathrm{g} / \mathrm{mL})$ induced high levels of IL-6 mRNA expression (Figure 3D) after $24 \mathrm{~h}$ incubation. The level of IL-6 expression in MSCs treated with PF68/p-MWCNT and PF68/MWCNT-OH was significantly higher $(* * P<0.01)$ than that in $P F 68 /$ MWCNT-COOH-treated MSCs at similar concentration. This trend is similar to that in ROS assay.

\subsubsection{Cell cycle}

To investigate whether the three types of PF68/MWCNTs influenced the cell cycle of MSCs, we measured the change in the percent synthesis phase of DNA [\%S] and percent post-synthesis phase of DNA [\%G2] in the cell cycle. The percentage of cells in G1 phase increased after treatment with the three types of PF68/MWCNTs compared with the untreated cells. Accordingly, the proliferation index (\%S and \%G2) of MSCs treated with three types of PF68/MWCNTs $(100 \mu \mathrm{g} / \mathrm{mL}$ respectively) 
decreased after $24 \mathrm{~h}$ of incubation (Figure 3E). The reduction in percent proliferation index was greater in PF68/p-MWCNT-treated MSCs than in cells treated with PF68/MWCNT-COOH and PF68/MWCNT-OH. Furthermore, the inhibition of cell cycle was significantly higher in cells treated with PF68/p-MWCNT (50 and 100 $\mu \mathrm{g} / \mathrm{mL}$ ) (Figure 3E; Figure S1; Table S2). These results indicate that all three types PF68/MWCNTs affected the percent proliferation index of MSCs.

\subsubsection{Cell apoptosis}

Flow cytometry analysis (Figure 3F; Figure S2) showed that a $24 \mathrm{~h}$ exposure to PF68/p-MWCNT, PF68/MWCNT-COOH, and PF68/MWCNT-OH $(100 \mu \mathrm{g} / \mathrm{mL})$ induced high apoptosis rates of $11.78 \%$, 9.86\%, and $10.30 \%$, respectively. Additionally, the apoptosis ratio increased with incubation time (Figure 3F). After 48 h exposure to PF68/p-MWCNT, PF68/MWCNT-COOH, and PF68/MWCNT-OH, the apoptotic rates of MSCs were 16.57\%, 15.53\%, and 15.92\%, correspondingly, whereas the apoptosis rates of MSCs after $72 \mathrm{~h}$ exposure were $30.26 \%, 24.71 \%$, and 26.61\%, respectively.These results indicated that PF68/p-MWCNT induced considerably higher apoptosis than PF68/MWCNT-COOH and PF68/MWCNT-OH, implying a time-dependent induction. This finding can explain the higher cytotoxicity of PF68/p-MWCNT over PF68/MWCNT-COOH and MWCNT-OH. Moreover, PF68 $(1 \% \mathrm{w} / \mathrm{v})$ did not induce significant apoptosis under similar conditions. This finding is consistent with the WST-1 results. 

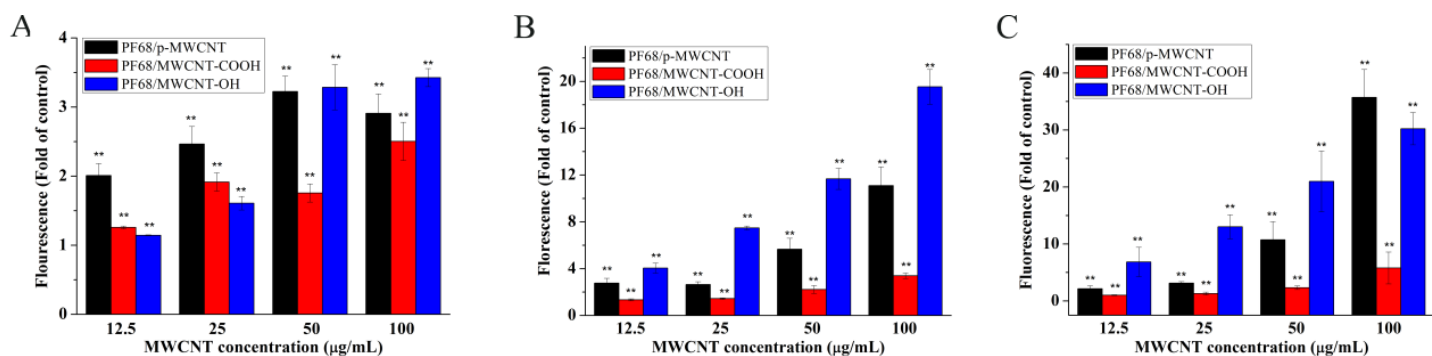

D

E
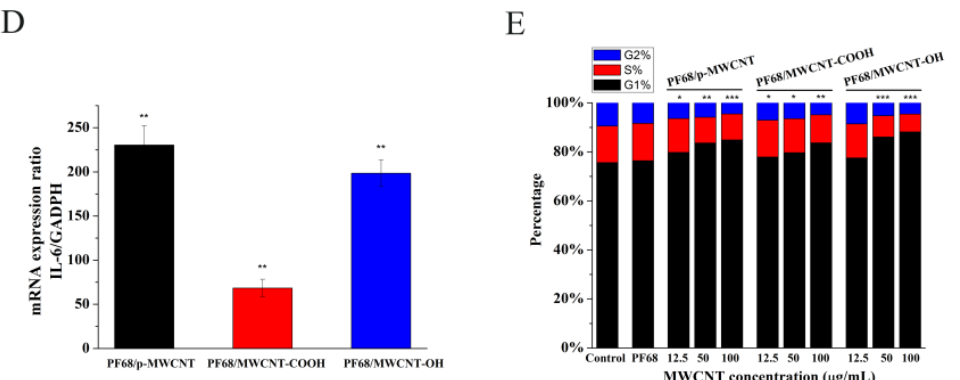

$\mathrm{F}$

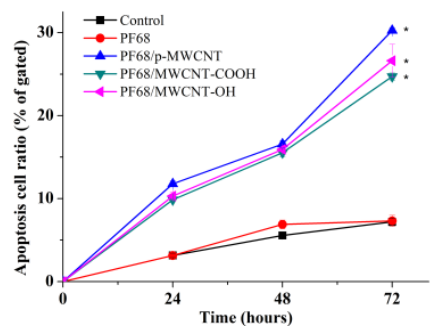

Figure 3.Production of ROS in MSCs after exposure to PF68/p-MWWCNT, PF68/MWCNT-COOH, and PF68/MWCNT-OH (12.5-100 $\mu \mathrm{g} / \mathrm{mL})$ for (A) 24h, (B) 48h, and (C) 72h. Data are expressed as means \pm standard deviation; $n=6, * P<0.05$, ** $P<0.01$.(D) Relative mRNA expression of IL-6 in MSCs cultured with PF68/p-MWCNT, PF68/MWCNT-COOH, and PF68/MWCNT-OH (12.5 $\mu \mathrm{g} / \mathrm{mL})$ for 24 h. GADPH expression was used as a loading control. Data are expressed as means \pm standard deviation; $n=3, * P<0.05, * * P<0.01$, $* * * P<0.001$. (E) Cell-cycle analysis of MSCs incubated with PF68 (1\% w/v), PF68/p-MWCNT, PF68/MWCNT-COOH, and PF68/MWCNT-OH for $24 \mathrm{~h} ; n=3, * P<0.05, * * P<0.01, * * * P<0.001$. (F)The apoptosis rate induced by exposure to $100 \mu \mathrm{g} / \mathrm{mL}$ PF68/MWCNTs using Annexin V-FITC and PI. Data are shown as mean \pm standard deviation obtained from three separate experiments. ${ }^{*} P<0.05$, $* * P<0.01, * * * P<0.001$ compared with the control.

\subsection{MWCNT internalization}

TEM results (Figures 4G-4O) demonstrated that all three types of PF68/MWCNTs 
penetrated into the MSCs after $24 \mathrm{~h}$ incubation. The TEM images (Figures 4A-4F) revealed no change to the cellular ultrastructure (mitochondria and endoplasmic reticulum) of PF68-treated MSCs compared with the unexposed MSCs. These findings indicated that PF68 (1\% w/v) did not adversely affect the cellular ultrastructure of MSCs, supporting the results above (Figures 4G-4O).
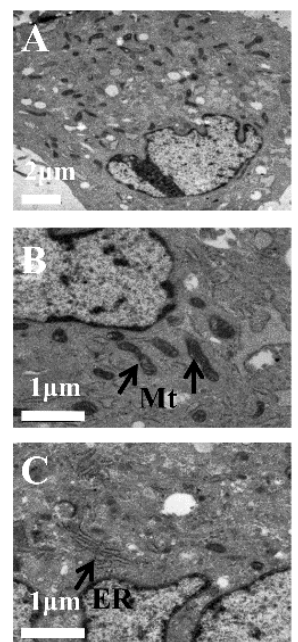

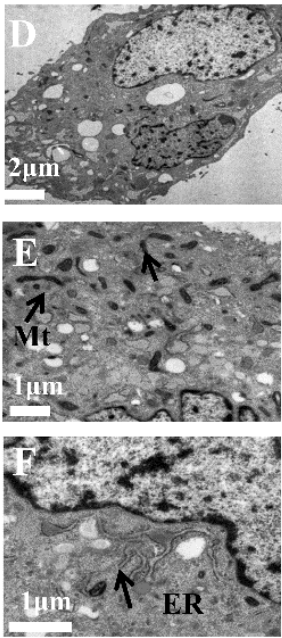

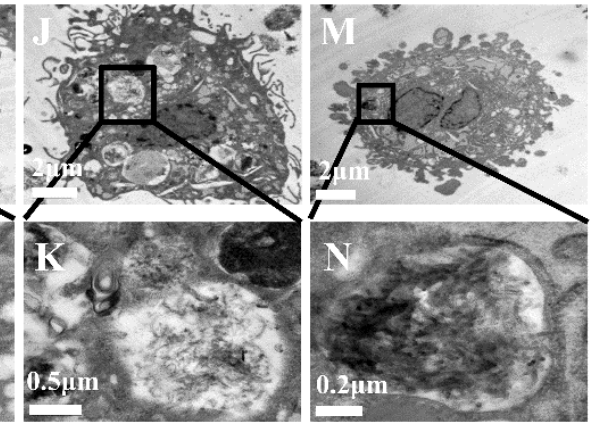

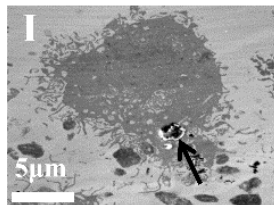

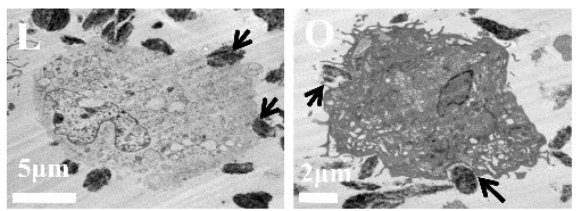

Figure 4.TEM observation of MSCs. (A-C) MSCs non-treated, and (D-F) MSCs treated with PF68.MSCs non-treated and treated with PF68 showed mitochondria (Mt) and endoplasmicreticulum (ER) (B, C, E and F, arrow). MSCs exposure to (G-I) PF68/p-MWCNT, $\quad$ (J-L) $\quad$ PF68/MWCNT-COOH, $\quad$ and $\quad$ (M-O) PF68/MWCNT-OH(12.5 $\mu \mathrm{g} / \mathrm{mL})$ for 24 h. MWCNT were observed either in cytoplasmic compartments or free in the cytoplasm (I, $\mathbf{L}$ and $\mathbf{O}$, arrow). MWCNT were observed penetrating into MSCs, (I) PF68/p-MWCNT group, (L) PF68/MWCNT-COOH group and (O) PF68/MWCNT-OH group.

\subsection{MSC surface markers, Cytoskeleton and cell adhesion}

Figure 5A shows that the third-generation BMSCs expressed surface antigens 
CD73 and CD44 but not CD45 and CD34. The level of purity obtained in this experiment was sufficient since more than $95 \%$ of the cells were tested positive. Furthermore, the expression of these BMSC surface markers did not significantly change after being treated with PF68/p-MWCNT, PF68/MWCNT-COOH, and PF68/MWCNT-OH (12.5 $\mu \mathrm{g} / \mathrm{mL})$ for $24 \mathrm{~h}$, respectively.

Adhesion, which is the first response of cells coming into contact with a biomaterial, regulates the subsequent biological behavior of cells. Cytoskeleton and cell adhesion-related proteins play vital roles in adhesion. Vinculin, a member of the cytoskeleton protein and sticky protein families, plays an important role in cell viability, proliferation, stretching, and synergistic action with other adhesive proteins, cytoskeletal proteins, and F-actin cytoskeleton. The confocal images (Figure 5B) revealed that exposure to the three types of PF68/MWCNTs $(12.5 \mu \mathrm{g} / \mathrm{mL})$ did not affect the intensity and distribution of vinculin and F-actin cytoskeleton in MSCs. 
A
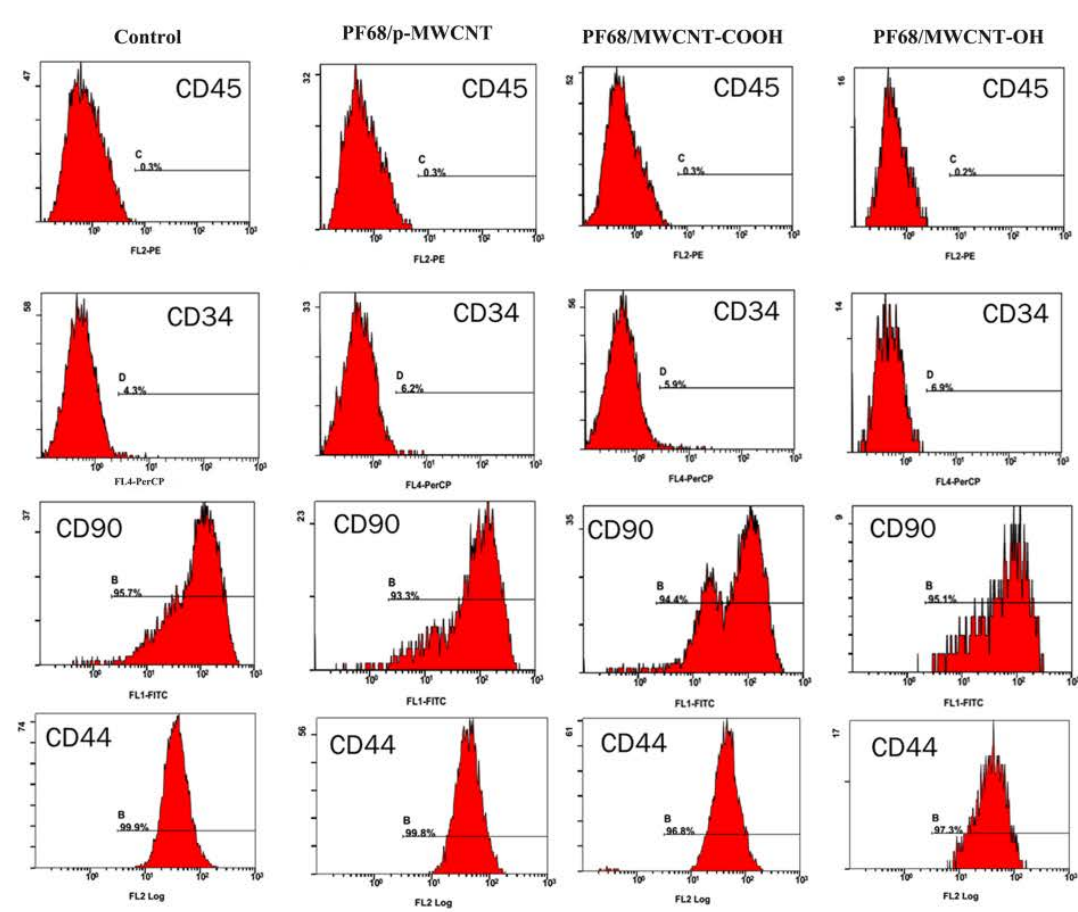

B

a

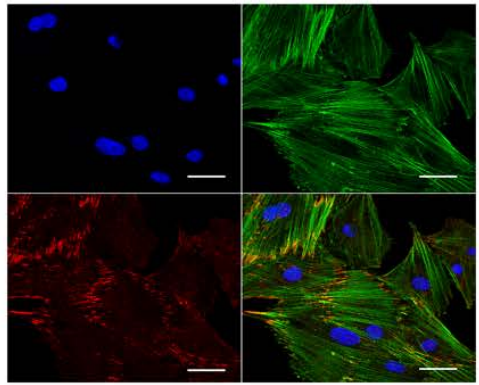

C

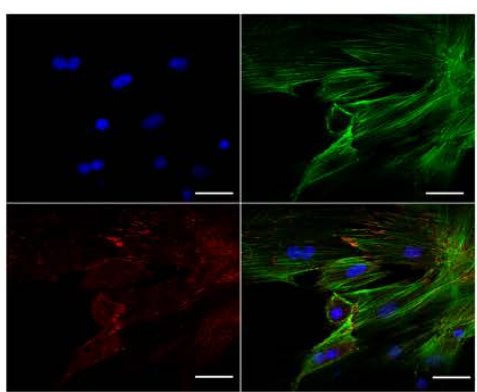

b

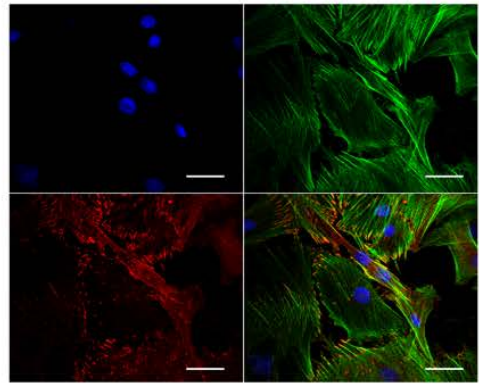

d

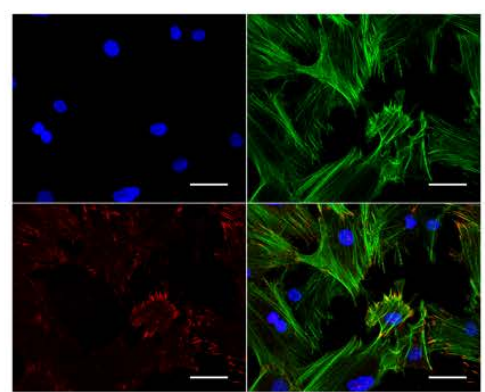

Figure 5. (A)Flow cytometry characterization of MSCs. Surface markers CD45 (-), CD34 (-), and CD90 (+) of MSCs under PF68/p-MWCNT, PF68/MWCNT-COOH, 
and PF68/MWCNT-OH $(12.5 \mu \mathrm{g} / \mathrm{mL})$ for $24 \mathrm{~h}$ or without CNT exposure. (B) Confocal microscopic images of MSCs (a) non-treated or incubated with (b) PF68/p-MWCNT, (c) PF68/MWCNT-COOH, and (d) PF68/MWCNT-OH (12.5 $\mu \mathrm{g} / \mathrm{mL}$ respectively) for $24 \mathrm{~h}$; MSCs vinculin (red), actin cytoskeleton (green), and cell nucleus (blue). Scale bar $=40 \mu \mathrm{m}$.

\subsection{Cell migration in vitro}

Transwell chamber was used to investigate the effects of PF68/MWCNTs on cell migration(Figure 6A). Figure 6B shows the representative images of the control MSCs and those treated with the three types of PF68/MWCNTs. Quantitative analysis (Figure 6C) showed that all three types of PF68/MWCNTs affected the migration ability of MSCs in vitro. Moreover, the migration ability of PF68/p-MWCNT-treated MSCs significantly decreased $(* * P<0.01)$ compared with that of the MSCs treated with PF68/MWCNT-OH and PF68/MWCNT-COOH. The results suggest that various functional groups reduced the effects of CNTs on migration of MSCs in vitro. 


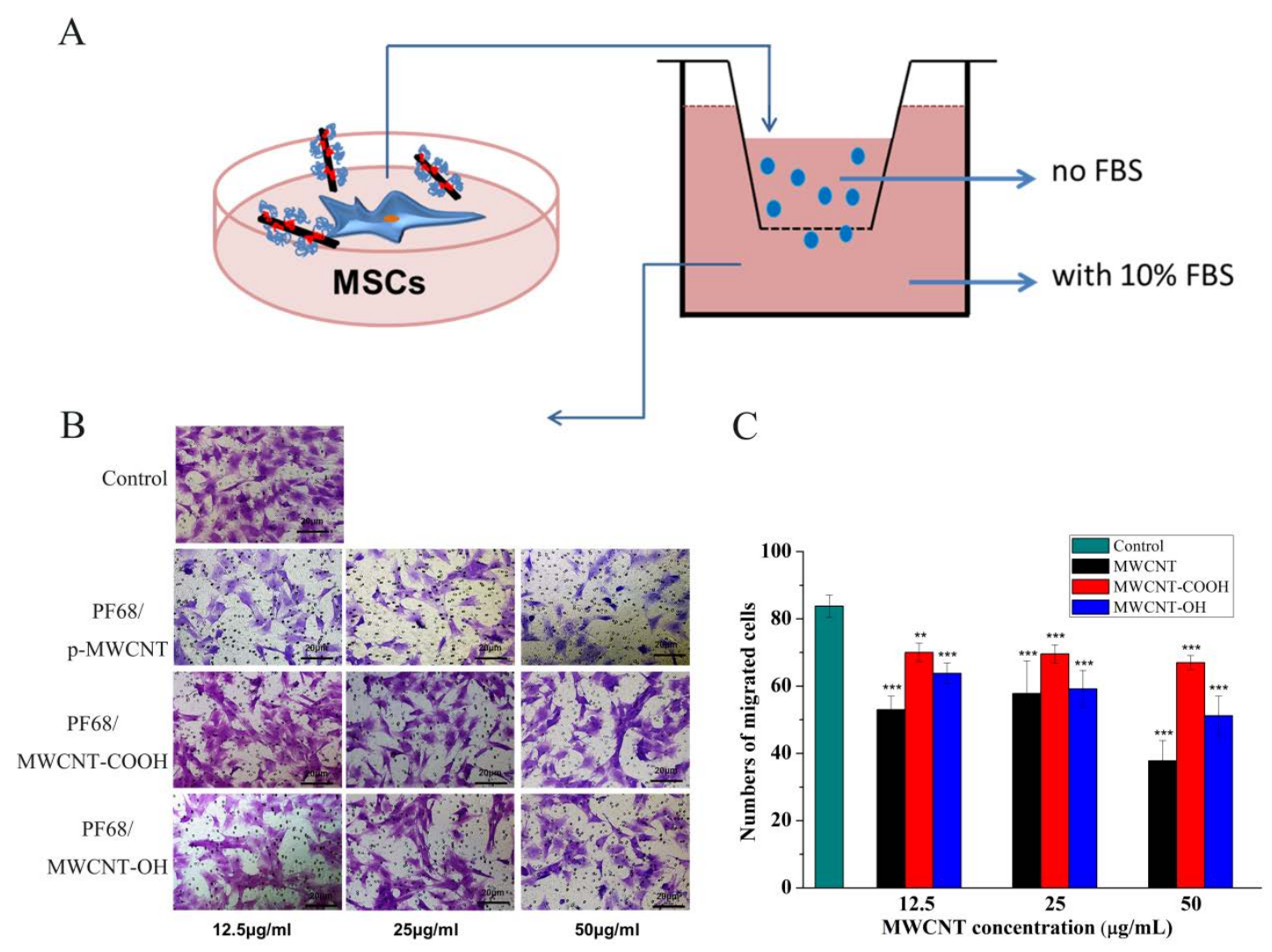

Figure 6.Transwell assay.(A) Experimental protocol for conditioned media experimentation MSCs were treated with three different types of PF68/MWCNT for 24 hours. The treated cells were then collected and seeded into a Millicell at an initial seeding density of $1 \times 10^{5}$ cells/cm² suspended in low-glucose DMEM (FBS-free). The Millicell was placed into a 24-well plate containing 10\% FBS in low-glucose DMEM, and the cells were allowed to migrate at $37^{\circ} \mathrm{C}$ for another 24 h. (B) Qualitative cell migration assay as shown by Transwell assay after $24 \mathrm{~h}$ culture. Scale bar $=20 \mu \mathrm{m}$. (C) Quantitative analysis of relative cell migration from B. Data are expressed as means \pm standard deviation; $n=6, * P<0.05, * * P<0.01, * * * P<0.001$. 


\subsection{Osteogenic differentiation}

Osteogenic differentiation of MSCs treated with the three types of PF68/MWCNTs was evaluated by ALP staining, ALP activity quantification and mRNA expression of osteocalcin and osteopontin (Figure 7). ALP is an early mineralization-related protein marker for osteogenesis of MSCs. The results showed that exposure to the three types of PF68/MWCNTs did affect the mineralization ability of MSCs. Furthermore, all three types of PF68/MWCNTs weakened the ALP activity of MSCs in a concentration-dependent manner compared with the control group. After culture for 7 days, the PF68/MWCNT-COOH-treated MSCs demonstrated higher ALP activity than those treated with PF68/p-MWCNT (Figure 7C). After cultured for 14 days, the PF68/MWCNT-COOH-treated MSCs showed significantly higher ALP activity than those treated with PF68/p-MWCNT and PF68/MWCNT-OH (Figure 7D).

Furthermore, the influence of PF68/MWCNTs on osteogenesis-related mRNA expression was investigated via reverse transcription polymerase chain reaction (Figure 7E). Osteocalcin (OCN) and osteopontin (OPN) are mature osteoblast markers of MSCs[33]. All three types of PF68/MWCNTs affected the OCN expression but showed no statistically significant effect on the OPN expression in MSCs. 

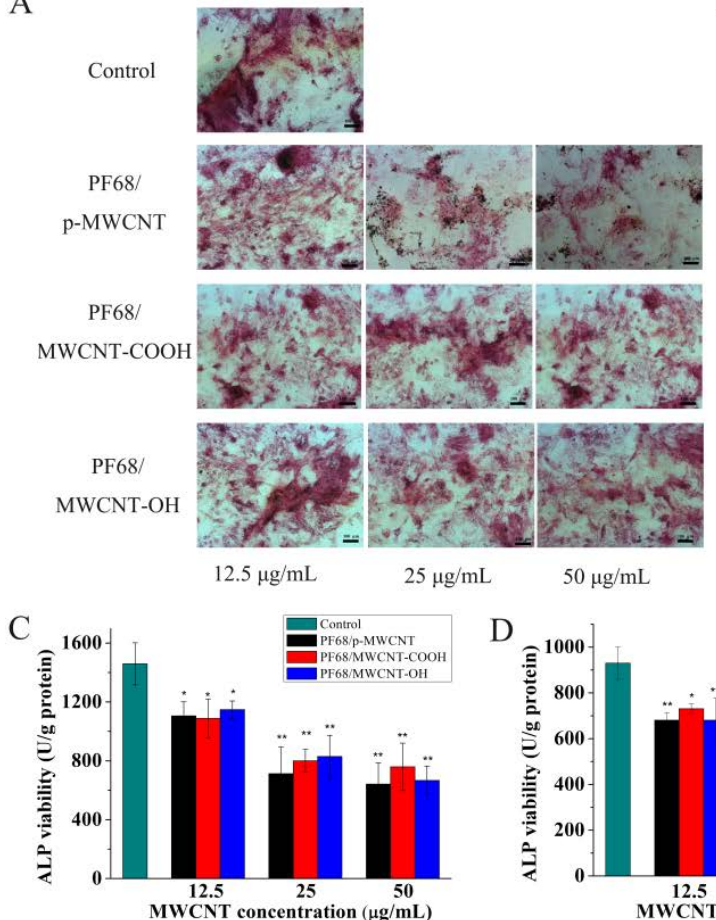
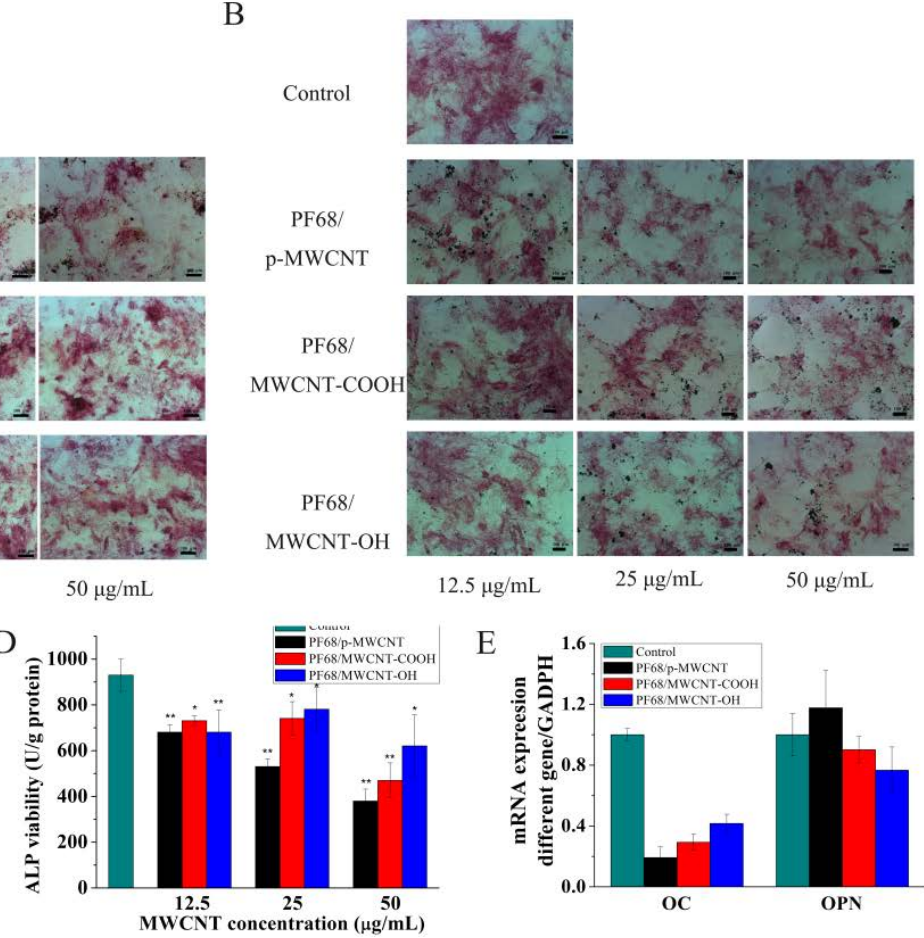

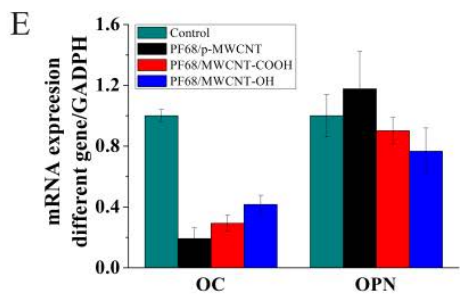

Figure 7.Effects of PF68/MWCNTs on osteogenic differentiation of MSCs. ALP staining of MSCs cultured with PF68/p-MWCNT, PF68/MWCNT-COOH, and PF68/MWCNT-OH (12.5-50 $\mu \mathrm{g} / \mathrm{mL})$ for $\mathbf{( A )} 7$ days and (B) 14 days. Bar $=100 \mu \mathrm{m}$. ALP level of MSCs cultured with p-MWCNT, MWCNT-COOH, and MWCNT-OH for (C) 7 days and (D) 14 days. (E) Relative mRNA expression of osteocalcin and osteopontin analyzed by real-time PCR. Data are expressed as means \pm standard deviation; $n=3,{ }^{*} P<0.05$, ${ }^{* *} P<0.01,{ }^{* * *} P<0.001$.

\subsection{In vivo biodistribution of PF68/MWCNT-treated MSCs}

Following $24 \mathrm{~h}$ exposure to the three types of PF68/MWCNTs $(12.5 \mu \mathrm{g} / \mathrm{mL}$ respectively), the biodistribution of MSCs (I.V.) did not change at $72 \mathrm{~h}$ after injection compared with the control group, in which MSCs were injected without PF68/MWCNT treatment (Figure 8A). Furthermore, the Dil-labeled MSCs in control, 
PF68/p-MWCNT, PF68/MWCNT-COOH, and PF68/MWCNT-OH groups were mainly observed in the lungs. We can preliminary conclude that PF68/p-MWCNT, PF68/MWCNT-COOH, and PF68/MWCNT-OH did not influence the in vivo biodistribution of MSCs.

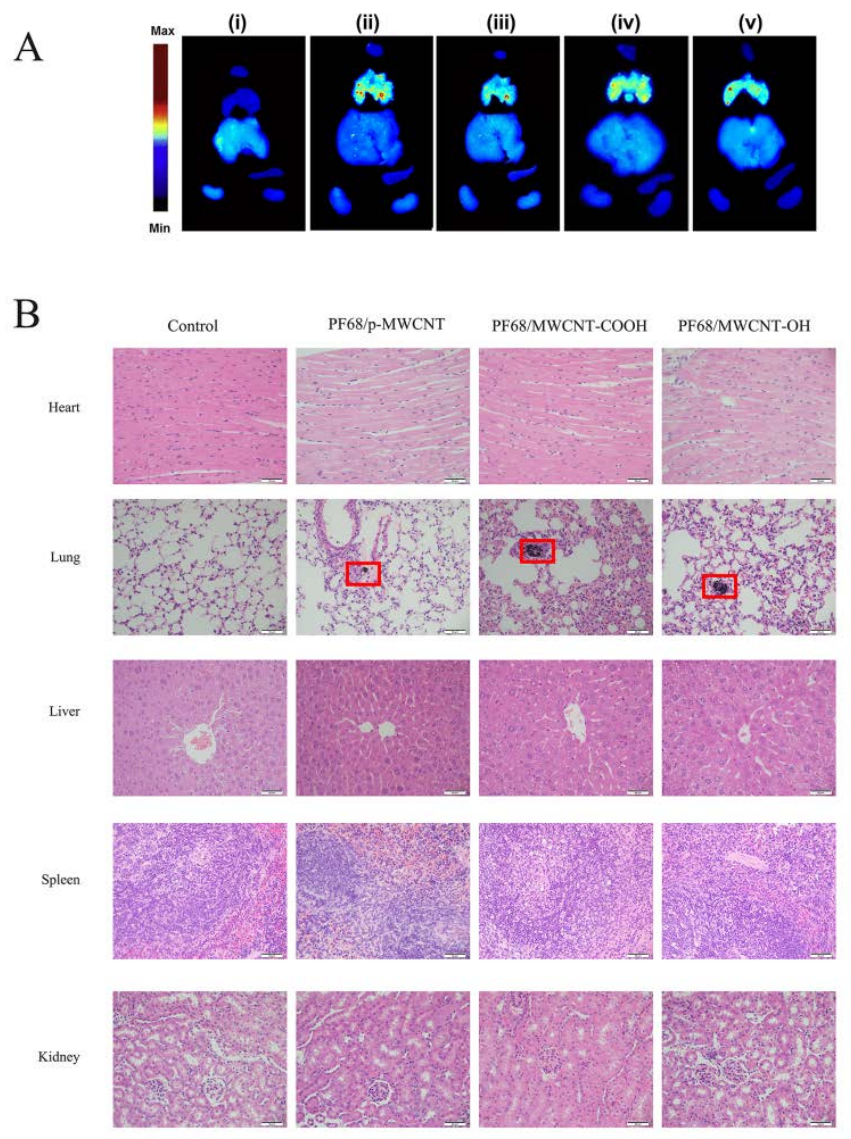

Figure 8.Biodistribution and HE staining.(A) In vivo biodistribution of Dil-labeled MSCs in nude mice at $72 \mathrm{~h}$ afterintravenous injection.Before the injection, MSCs were incubated with PF68/p-MWCNT, PF68/MWCNT-COOH, and PF68/MWCNT-OH(12.5ug/ml respectively) for 24 h. Nude mice was injected (i) PBS, (ii) MSCs, (iii) MSCs exposed to PF68/p-MWCNT, (iv) MSCs exposed to PF68/MWCNT-COOH, and (v) MSCs exposed to PF68/MWCNT-OH.(B) Representative photomicrographs in bright-field microscopy of MSCs unexposed to 
MWCNTs or exposed to PF68/p-MWCNT, PF68/MWCNT-COOH, and PF68/MWCNT-OH (12.5 $\mu \mathrm{g} / \mathrm{mL}$ respectively) for $24 \mathrm{~h}$.

\subsection{Immunohistochemistry}

After HE coloration of paraffin section of brain, lung, liver, spleen and kidney, no significant alterations were observed in liver, spleen and kidney in all groups injected MSCs treated with PF68/p-MWCNT, PF68/MWCNT-COOH and PF68/MWCNT-OH at concentration of $12.5 \mu \mathrm{g} / \mathrm{ml}$ for $24 \mathrm{~h}$, respectively (Figure 8B). But the inflammatory response was found in lung when injecting MSCs treated with PF68/p-MWCNT, PF68/MWCNT-COOH and PF68/MWCNT-OH. Also the CNTs could be found in the paraffin section of lung.

\section{Discussion}

In the investigation of toxicity, the major challenge is the aggregation of CNTs due to the strong Van der Waals binding energies[34]. This makes the cytotoxic research of CNTs very complex. Chemical functionalization is one widely used strategy to improve the dispersibility of $\mathrm{CNTs}[35,36] . I t$ has been reported that chemical functionalized CNTs are less toxic compared with the pristine CNTs. Mooney et al revealed functionalized CNTs were easier to disperse in hMSC medium with no significant effect on adipogenesis, osteogenesis, or chondrogenesis of hMSC and -COOH functionalized SWCNT was least toxic [37], which was the first study to report the effect of CNTs on hMSC.Bari et al. proved functionalized SWCNT 
enhancedex vivo expansionof hematopoietic stem and progenitor cells in human umbilical cord blood [5]. Nouaraet al. studiedthe toxicity of MWCNT toC.elegansand revealed chemical functionalizationof MWCNT prevented its adverse effects to the reproductive system of C.elegans [38]. Liu et al. revealed that MWCNT modified with carboxyl group could reduce its toxicity to LO2 cells byinhibitingthe signal pathway of mitochondria mediated apoptosis [39]. There is another possibility that functionalized CNTsare easier to be eliminated than pristine CNTsthat might accumulate intracellularlythus reduced reproductive capacity,which is consistent with Allenet al.whoreported carboxylated SWCNTs was biodegraded by the horseradish peroxidase (HRP) in natural enzymatic catalysis way[40].Also Liu et al. demonstrated that functionalized CNTs could be degraded by oxidative enzymes and produced extensive amount of nanotube debris. But non-functionalized SWCNTs were resistant to oxidative enzymes and had no morphological changeswhen exposed to the same biological oxidative conditions [41].

In addition, non-covalent adsorption of polymeric surfactants has made progress and advances on dispersion of CNTs. The noncovalent approach, involving adsorption of chemical moieties on the CNTs surface via $\pi-\pi$ stacking interaction or coulomb attraction, is superior that it avoids defects of the CNTs surface and alters the electrical properties of CNTs [42]. Copolymer-CNTs composites are expected to have good characteristics of CNTs. A wide variety of copolymers have been investigated for dispersion of CNTs [20-21,43-44]. Functionalization of CNTs with biologically relevant and effective polymers was considered as a promising strategy to provide 
good biocompatibility for CNTs application in MSCs. Many types of non-covalent modification have generated variouscopolymer-coated CNTs [45]. Pluronic, which consists of a central polyoxypropylene molecule and two hydrophilic chains flanked on both sides, is widely used to disperse nanomaterials including CNTs for biomedical applications. Bardi et al. demonstrated that MWCNTs coated with Pluronic F-127 (PF127) surfactant could be injected into the mouse cerebral cortex without causing degeneration of the neurons surrounding the site of injection [46]; they also showed that reasonable concentrations of PF127-coated MWCNTs were not toxic for adipocytes and do not interfere with their differentiation processes [47]. PF68 has been demonstrated to suppress cell apoptosis and is suggested to use as a cell protective agent in the treatment of thrombosis, stroke, and myocardial infarction $[25,26]$.

In this study, we conducted a systemic study on the toxicological impact of three different types of PF68 modified MWCNTs to MSCs. We found that all types of non-coated MWCNTs suppressed cell viability and proliferation of MSCs (Figure 2D-2F), while PF68 coated MWCNTs had enhanced dispersibility and shown improved biosafety to BMSCs (Figure1). We revealed the time- and dose-dependent effects of PF68/p-MWCNT, PF68/MWCNT-COOH, and PF68/MWCNT-OH on the viability, proliferation, migration, differentiation, and inflammatory response of MSCs.The WST-1 assay results (Figures 2) showed that cell viability (after $24 \mathrm{~h}$ exposure) was not significantly affected by the three types of PF68/MWCNTs. A slight apoptosis induction (approximately 10\%) was detected in treatments of the 
three types of PF68/MWCNTs (50 and $100 \mu \mathrm{g} / \mathrm{mL}$, Figure 3F).With prolonged exposure, the viability of MSCs decreased significantly for all three types of PF68/MWCNTs; also massive ROS production induced, which is closely related to immunological reaction (Figure 3A-3C) and lead to alterations in the cell cycle (Figure 3E). It is speculated that PF68 is loosely adsorbed on the MWCNT surface, thereby reducing the MWCNT toxicity upon cell incubation within 24 h. However, prolonged incubation and cellular uptake lead to the dissociation of PF68 and MWCNTs, consequently inducing massive ROS and high IL-6 expression level in stem cells, which gave rise to cell cycle arrest and reduced viability of MSCs.

Furthermore, PF68/MWCNT-COOH and PF68/MWCNT-OH showed less side effects on MSCs proliferation than that of PF68/p-MWCNT, which corroborated well with previous reports that a high degree of sidewall functionalization reduced the cytotoxicity of CNT samples [37-39,48-50].In addition, the three types of PF68/MWCNTs influenced MSCs migration at varying degrees (Figures 6) but without influencing the biodistribution of MSCs (Figure 8A).

PF68 was reported to have shear protective function minimizing cell death [25, 26] and could be incorporated into the cell plasma membrane to enter cells[51].Granite et al. demonstrated the Single-walled CNT (SWCNT) surface was thin bundled with loosely adsorbed polymer chains [52]. They also found fluorescent PF68 enters the cells and intracellular PF68 was then eliminated by CHO cells [53]. Accordingly, we speculate PF68 is loosely adsorbed on the surface of CNT to reduce the toxicity when incubated with cells. However, long time incubation may lead to dissociation of 
surface PF68, and CNTs without PF68 coated wouldinduce ROS and IL-6 expression, affecting cell cycle, proliferation and migration.

\section{Conclusion}

PF68 coating can improve the biocompatibility of MWCNTs to MSCs. However, toxicity may arise after prolonged exposure (48-72 h), and the toxicity tendency still depends on the initial surface properties of the encapsulated MWCNTs. PF68/p-MWCNT and PF68/MWCNT-OH with relatively large hydrodynamic sizes could increase the ROS release level and IL-6 expression level, thereby induced cell apoptosis and cell-cycle arrest, suppressed MSCs migration, and influenced osteogenic differentiation. The surface markers, cytoskeleton, and in vivo biodistribution of MSCs were not altered after exposure to any of the three types of PF68/MWCNTs; this finding is beneficial for the application of PF68 coated functionalized MWCNTs in stem cell research.

\section{List of Abbreviations}

CNT: Carbon nanotubes; SWCNT: Single-walled CNT; MWCNT: Multi-walled CNT ; MSCs: Mesenchymal stem cells; PF68: Pluronic F-68; PF127:Pluronic F-127 ; P-MWCNT: Pristine MWCNT; MWCNT-COOH: CarboxylatedMWCNT; MWCNT -OH: Hydroxylated MWCNT; PF68/MWCNT: PF68-coated MWCNT; PF68/pMWCNT: PF-68-coated p-MWCNT; PF68/MWCNT-COOH: PF68-coated MWCNT -COOH; PF68/MWCNT-OH: PF68-coated MWCNT-OH;ROS: Reactive oxygen 
species; IL-6: Interleukin-6; ALP: alkaline phosphatase ; OCN: Osteocalcin ; OPN: Osteopontin ; H\&E: Hematoxylin and eosin.

\section{Acknowledgements}

This study was supported in part by grants from National Science Foundation of China (Grant No. 81271955). We are grateful to the Core Facility of Zhejiang University of Medicine for technical assistance in confocal laser-scanning microscopy and Flow cytometric analysis. Also we would like to acknowledge the Analysis Center of Agrobiology and Environmental Science for assistance in transmission electron microscopy service. 


\section{Reference}

[1] Tran C, Damaser MS. Stem cells as drug delivery methods: application of stem cell secretome for regeneration. Adv Drug Deliv Rev. 2015;82-83:1-11.

[2] Karantalis V, Hare JM. Use of mesenchymal stem cells for therapy of cardiac disease. Circ Res. 2015;116:1413-30.

[3] Keating A. Mesenchymal stromal cells: new directions. Cell Stem Cell. 2012;10:709-16.

[4] Ferreira L, Karp JM, Nobre L, Langer R. New Opportunities: The Use of Nanotechnologies to Manipulate and Track Stem Cells. Cell Stem Cell. 2008;3:136-46.

[5] Bari S, Chu PPY, Lim A, Fan X, Gay FPH, Bunte RM, et al. Protective role of functionalized single walled carbon nanotubes enhance ex vivo expansion of hematopoietic stem and progenitor cells in human umbilical cord blood. Nanomedicine: Nanotechnology Biology and Medicine. 2013;9:1304-16.

[6] Zhao B, Hu H, Mandal SK, Haddon RC. A bone mimic based on the self-assembly of hydroxyapatite on chemically functionalized single-walled carbon nanotubes. Chem Mater. 2005;17:3235-41.

[7] Mattson MP, Haddon RC, Rao AM. Molecular functionalization of carbon nanotubes and use as substrates for neuronal growth. $\mathrm{J}$ Mol Neurosci. 2000;14:175-82.

[8] Lamanna G, Garofalo A, Popa G, Wilhelm C, Begin-Colin S, Felder-Flesch D, et al. Endowing carbon nanotubes with superparamagnetic properties: applications for 
cell labeling, MRI cell tracking and magnetic manipulations. Nanoscale. 2013;5:4412-21.

[9] Hilal G, Weibing L, Peng X, James X, Jie C. Magnetic carbon nanotube labelling for haematopoietic stem/progenitor cell tracking. Nanotechnology. 2010;21:155101.

[10] Shim M, Kam NWS, Chen RJ, Li YM, Dai HJ. Functionalization of carbon nanotubes for biocompatibility and biomolecular recognition. Nano lett. 2002;2:285-8.

[11] Bianco A, Kostarelos K, Prato M. Applications of carbon nanotubes in drug delivery. Curr Opin Chem Biol. 2005;9:674-9.

[12] Cifuentes-Rius A, de Pablo A, Ramos-Pérez V, Borrós S. Tailoring Carbon Nanotubes Surface for Gene Delivery Applications. Plasma Processes Polym. 2014;11:704-13.

[13] Al-Jamal KT, Toma FM, Yilmazer A, Ali-Boucetta H, Nunes A, Herrero MA, et al. Enhanced cellular internalization and gene silencing with a series of cationic dendron-multiwalled carbon nanotube:siRNA complexes. FASEB J. 2010;24:4354-65.

[14] Liu D, Yi C, Zhang D, Zhang J, Yang M. Inhibition of Proliferation and Differentiation of Mesenchymal Stem Cells by Carboxylated Carbon Nanotubes. ACS Nano. 2010;4:2185-95.

[15] Zhu L, Chang DW, Dai L, Hong Y. DNA Damage Induced by Multiwalled Carbon Nanotubes in Mouse Embryonic Stem Cells. Nano Lett. 2007;7:3592-7.

[16] Akhavan O, Ghaderi E, Emamy H, Akhavan F. Genotoxicity of graphene 
nanoribbons in human mesenchymal stem cells. Carbon. 2013;54:419-31.

[17] Pietroiusti A, Massimiani M, Fenoglio I, Colonna M, Valentini F, Palleschi G, et al. Low Doses of Pristine and Oxidized Single-Wall Carbon Nanotubes Affect Mammalian Embryonic Development. ACS Nano. 2011;5:4624-33.

[18] Kalbacova M, Kalbac M, Dunsch L, Kataura H, Hempel U. The study of the interaction of human mesenchymal stem cells and monocytes/macrophages with single-walled carbon nanotube films. Plasma Processes Polym. 2006;243:3514-8.

[19] Oh H, Sim J, Ju SY. Binding affinities and thermodynamics of noncovalent functionalization of carbon nanotubes with surfactants. Langmuir. 2013;29:11154-62. [20] Jiang L, Gao L, Sun J. Production of aqueous colloidal dispersions of carbon nanotubes. J Colloid Interf Sci. 2003;260:89-94.

[21] Monteiro-Riviere NA, Inman AO, Wang YY, Nemanich RJ. Surfactant effects on carbon nanotube interactions with human keratinocytes. Nanomedicine: Nanotechnology, Biology and Medicine. 2005;1:293-9.

[22] Chao TI, Xiang S, Chen CS, Chin WC, Nelson AJ, Wang C, et al. Carbon nanotubes promote neuron differentiation from human embryonic stem cells. Biochem Biophy Res Co. 2009;384:426-30.

[23] Cho SY, Yun YS, Kim ES, Kim MS, Jin HJ. Stem cell response to multiwalled carbon nanotube-incorporated regenerated silk fibroin films. J Nanosci Nanotechnol. 2011;11:801-5.

[24] Nayak TR, Jian L, Phua LC, Ho HK, Ren Y, Pastorin G. Thin Films of Functionalized Multiwalled Carbon Nanotubes as Suitable Scaffold Materials for 
Stem Cells Proliferation and Bone Formation. ACS Nano. 2010;4:7717-25.

[25] Kelly R, Hursey T, Patel R, Parrillo J, Schaer G. Effect of Poloxamer 188 on Collateral Blood Flow, Myocardial Infarct Size, and Left Ventricular Function in a Canine Model of Prolonged (3-Hour) Coronary Occlusion and Reperfusion. J Thromb Thrombolys. 1998;5:239-47.

[26] Malda J, van den Brink P, Meeuwse P, Grojec M, Martens DE, Tramper J, et al. Effect of oxygen tension on adult articular chondrocytes in microcarrier bioreactor culture. Tissue Eng. 2004;10:987-94.

[27] Sa Santos S, Fonseca LL, Monteiro MA, Carrondo MJ, Alves PM. Culturing primary brain astrocytes under a fully controlled environment in a novel bioreactor. $\mathrm{J}$ Neurosci Res. 2005;79:26-32.

[28] Yu X, Botchwey EA, Levine EM, Pollack SR, Laurencin CT. Bioreactor-based bone tissue engineering: the influence of dynamic flow on osteoblast phenotypic expression and matrix mineralization. Proc Natl Acad Sci. 2004;101:11203-8.

[29] Luo C, Li Q, Gao Y, Shen X, Ma L, Wu Q, et al. Poloxamer 188 Attenuates Cerebral Hypoxia/Ischemia Injury in Parallel with Preventing Mitochondrial Membrane Permeabilization and Autophagic Activation. J Mol Neurosci. 2015;56:988-98.

[30] Mooney E, Mackle JN, Blond DJP, O'Cearbhaill E, Shaw G, Blau WJ, et al. The electrical stimulation of carbon nanotubes to provide a cardiomimetic cue to MSCs. Biomaterials. 2012;33:6132-9.

[31] Li XY, Zhang Y, Qi GX. Evaluation of isolation methods and culture conditions 
for rat bone marrow mesenchymal stem cells. Cytotechnology. 2013;65:323-34.

[32] Worle-Knirsch JM, Pulskamp K, Krug HF. Oops they did it again! Carbon nanotubes hoax scientists in viability assays. Nano Lett. 2006;6:1261-8.

[33] Dalby MJ, McCloy D, Robertson M, Wilkinson CD, Oreffo RO. Osteoprogenitor response to defined topographies with nanoscale depths. Biomaterials. 2006;27:1306-15.

[34] Huang YY, Terentjev EM. Dispersion of Carbon Nanotubes: Mixing, Sonication, Stabilization, and Composite Properties. Polymers. 2012;4:275-95.

[35] Kim SW, Kim T, Kim YS, Choi HS, Lim HJ, Yang SJ, et al. Surface modifications for the effective dispersion of carbon nanotubes in solvents and polymers. Carbon. 2012;50:3-33.

[36] Lee J, Kim M, Hong CK, Shim SE. Measurement of the dispersion stability of pristine and surface-modified multiwalled carbon nanotubes in various nonpolar and polar solvents. Meas Sci Technol. 2007;18:3707-12.

[37] Mooney E, Dockery P, Greiser U, Murphy M, Barron V. Carbon nanotubes and mesenchymal stem cells: biocompatibility, proliferation and differentiation. Nano Lett. 2008;8:2137-43.

[38] Nouara A, Wu Q, Li Y, Tang M, Wang H, Zhao Y, et al. Carboxylic acid functionalization prevents the translocation of multi-walled carbon nanotubes at predicted environmentally relevant concentrations into targeted organs of nematode Caenorhabditis elegans. Nanoscale. 2013;5:6088-96.

[39] Liu Z, Dong X, Song L, Zhang H, Liu L, Zhu D, et al. Carboxylation of 
multiwalled carbon nanotube enhanced its biocompatibility with L02 cells through decreased activation of mitochondrial apoptotic pathway. J Biomed Mater Res A. 2014;102:665-73.

[40] Allen BL, Kichambare PD, Gou P, Vlasova, II, Kapralov AA, Konduru N, et al. Biodegradation of single-walled carbon nanotubes through enzymatic catalysis. Nano Lett. 2008;8:3899-903.

[41] Liu X, Hurt RH, Kane AB. Biodurability of Single-Walled Carbon Nanotubes Depends on Surface Functionalization. Carbon N Y. 2010;48:1961-9.

[42] Manivannan S, Jeong I, Ryu J, Lee C, Kim K, Jang J, et al. Dispersion of single-walled carbon nanotubes in aqueous and organic solvents through a polymer wrapping functionalization. J MaterSci. 2009;20:223-9.

[43] Backes C. Results and Discussion. Noncovalent Functionalization of Carbon Nanotubes: Springer Berlin Heidelberg; 2012. p. 41-179.

[44] Xie XL, Mai YW, Zhou XP. Dispersion and alignment of carbon nanotubes in polymer matrix: A review. Mat Sci Eng R. 2005;49:89-112.

[45] Rastogi R, Kaushal R, Tripathi SK, Sharma AL, Kaur I, Bharadwaj LM. Comparative study of carbon nanotube dispersion using surfactants. J Colloid Interf Sci. 2008;328:421-8.

[46] Bardi G, Tognini P, Ciofani G, Raffa V, Costa M, Pizzorusso T. Pluronic-coated carbon nanotubes do not induce degeneration of cortical neurons in vivo and in vitro. Nanomedicine: Nanotechnology, Biology and Medicine. 2009;5:96-104.

[47] Bardi G, Vittorio O, Maffei M, Pizzorusso T, Costa M. Adipocytes differentiation 
in the presence of Pluronic F127-coated carbon nanotubes. Nanomedicine: Nanotechnology, Biology and Medicine. 2009;5:378-81.

[48] Patzke GR, Krumeich F, Nesper R. Oxidic nanotubes and nanorods - Anisotropic modules for a future nanotechnology. Angew ChemInt Edit. 2002;41:2446-61.

[49] Mahmoudi M, Azadmanesh K, Shokrgozar MA, Journeay WS, Laurent S. Effect of Nanoparticles on the Cell Life Cycle. Chem Rev. 2011;111:3407-32.

[50] Sayes CM, Liang F, Hudson JL, Mendez J, Guo W, Beach JM, et al. Functionalization density dependence of single-walled carbon nanotubes cytotoxicity in vitro. Toxicol Lett. 2006;161:135-42.

[51] Firestone MA, Seifert S. Interaction of nonionic PEO-PPO diblock copolymers with lipid bilayers. Biomacromolecules. 2005;6:2678-87.

[52] Granite M, Radulescu A, Cohen Y. Small-Angle Neutron Scattering from Aqueous Dispersions of Single-Walled Carbon Nanotubes with Pluronic F127 and Poly(vinylpyrrolidone). Langmuir. 2012;28:11025-31.

[53] Gigout A, Buschmann MD, Jolicoeur $M$. The fate of Pluronic F-68 in chondrocytes and CHO cells. Biotechnol Bioeng. 2008;100:975-87. 